\title{
Assessment of Known Risk Factors for Dengue Transmission in Haraincha Village Development Committee of Eastern Nepal
}

\author{
Parajuli $S B,{ }^{1 *} K C$ Heera $^{2}$
}

\section{Affiliation:}

1. Lecturer, Department of Community Medicine, Birat Medical College \& Teaching Hospital, Tankisinuwari-02, Morang, Nepal.

2. MSc. Nursing Student, B. P. Koirala Institute of Health Sciences, Dharan-18, Sunsari, Nepal.

\section{ARTICLE INFO \\ Article History \\ Received : 27 July, 2016 \\ Accepted : 27 Aug, 2016 \\ Published : $20 \mathrm{Dec}, 2016$}

(c) Authors retain copyright and grant the journal right of first publication with the work simultaneously licensed under Creative Commons Attribution License CC - BY 4.0 that allows others to share the work with an acknowledgement of the work's authorship and initial publication in this journal.

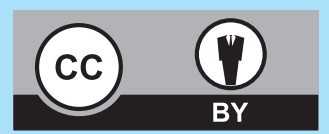

* Corresponding Author Dr. Surya B. Parajuli Lecturer Department of Community Medicine Birat Medical College \& Teaching Hospital Tankisinuwari-02, Morang, Nepal Email: info@suryaparajuli.com.np ORCID ID : 0000-0003-0386-9273

\section{Citation}

Parajuli SB, KC Heera. Assessment of Known Risk Factors for Dengue Transmission in Haraincha Village Development Committee of Eastern Nepal. BJHS 2016; 1 (1) 1:3-7.

\section{ABSTRACT}

\section{Introduction}

Currently dengue is a worldwide public health problem. Almost half of world's populations are at risk of dengue. The first case was reported from Nepal in 2004, since then major outbreaks occurred in the year 2006, 2010, 2012 and 2013. As Jhapa district had outbreak in 2012 and 2013, there is a high chance of outbreak in Morang district also. There might be presence of many known risk factor for dengue transmission at Haraincha Village Development Committee (VDC).

\section{Objective}

To assess the known risk factor associated with dengue transmission in Haraincha Village Development Committee of Morang district of Eastern Nepal.

\section{Methodology}

Community based cross-sectional study was conducted from $15^{\text {th }}$ October 2013 to $30^{\text {th }}$ November 2013 in Haraincha VDC of Morang district. The data was collected from 122 households by means of interview using a semi structured questionnaires and direct observation after taking informed consent. We observed the known risk factor of possible dengue transmission. Data were entered into Microsoft excel and analyzed by using SPSS.

\section{Results}

The mean age of the respondent was 38 years with male predominance (61.5\%). Only $7.4 \%$ were illiterate. The major occupation was agriculture (45.9\%). Fifty four percent were above the poverty line. Two percent had history of dengue contracted outside the country. Common risk factors observed were poor drainage system (79\%), poor natural light (75\%), paddy field nearby household (51\%), water filled open containers (44\%), big plant near household (31\%) and flower vases (26\%) etc.

\section{Conclusion}

The known risk factors for dengue transmission were present in Haraincha Village Development Committee.

\section{KEYWORDS}

Dengue, eastern Nepal, riskfactors, transmission 


\section{INTRODUCTION}

Dengue, a viral disease transmitted by mosquito has rapidly spreading in all regions of World Health Organization (WHO) in recent years. Dengue virus is transmitted by female Aedes aegypti and to a lesser extent Aedes albopictus mosquitoes species. Aedes also transmits yellow fever, chikungunya, and Zika infection. Dengue is widespread in tropical region with local variations which is influenced by rainfall, temperature and unplanned rapid urbanization. ${ }^{1}$ In 1635 AD first epidemic was recorded in the French West Indies. Scientist Rush was probably describing dengue first time when he wrote of "break-bone fever" occurring in Philadelphia in $1780{ }^{2}$ Recent decades, the incidence of dengue has grown dramatically around the world. Due to under-reporting and misclassification the actual numbers of dengue were low. One recent estimate indicates that, there were 390 million dengue infections every year of which 96 million manifest with clinical features having few severities. ${ }^{3}$ Another study reported that, about 3.9 billion people, in 128 countries, are at risk of infection with dengue viruses. ${ }^{4}$ About 2.5 billion people around the world living in dengue endemic countries 1.3 billion live in 10 countries of the South-East Asia region of WHO. Nepal reported its first case in November 2004 from Chitwan district in Japanese volunteer. Since then Nepal had reported 32 cases (2006), 27 cases (2007), 10 cases (2008), 30 cases (2009), 917 cases with 5 deaths (2010), 79 cases (2011), 183 cases (2012), 700 cases (2013). At Jhapa district alone 72 confirmed cases were reported in 2012. ${ }^{5}$ There are four distinct, but closely related, serotypes of the dengue virus namely DEN-1, DEN-2, DEN-3 and DEN-4. Recovery from dengue infection by one serotype of dengue virus provides immunity for life time against that particular serotype but no cross immunity to the other serotypes of dengue virus. Subsequent infections by other serotypes may increase the risk of severe dengue. ${ }^{6}$ The two major vectors of dengue transmission are peri-domestic and day biter, breeds mainly on clean stagnated water collected in water tanks, pools, coolers, flower vases, coconut shells, construction sites, overhead uncovered or partially covered water tanks, discarded buckets, artificial ponds, cans, bottles and automobile tires which are not emptied and cleaned periodically. In indoors the mosquitoes rest on various objects such as in closets and other dark places. Outside, they rest in shady and cool places. Aedes mosquito can fly up to a limited distance of $\mathbf{4 0 0}$ meters but can spread over long distances in various types of vehicles used by man. The outbreaks of dengue fever are most likely to occur in postmonsoon season when the breeding of the mosquitoes is highest. ${ }^{2}$ Monkeys and humans both are amplifying hosts and the virus is maintained by mosquitoes transovarially via eggs. The spread of infection occurs through the movement of the host (man) as the vectors, although movements of Aedes are very restricted. ${ }^{5}$ Regarding knowledge about preventive measures, majority (70.3\%) knew about mosquito repellents like mat, liquid vaporizers and coils. ${ }^{7}$ As the clinical pattern of dengue remains asymptomatic in more than $50 \%$ cases and also people often get confused with viral illness, it is vital to recognize at the earliest the signs and symptoms, multisystem involvement pattern in dengue to reduce the mortality. The best way to control dengue outbreak is to find possible risk factor for dengue transmission and its better management. Furthermore, studies on this topic are deficient in Nepal and work need to be done to find the present status regarding known risk factor for transmission of dengue and make efforts to make it worthwhile task. The objective of the study was to assess the existing known factors in Haraincha Village Development Committee of eastern Nepal.

\section{METHODOLOGY}

From $15^{\text {th }}$ October 2013 to $30^{\text {th }}$ November 2013 in Haraincha Village Development Committee of Morang District, a community based cross-sectional study was conducted. Data was collected from 122 households by means of interview using a pretested semi structurede questionnaires and direct observation of known risk factors of dengue transmission. The sample size was calculated based on the similar research conducted in Chitwan district of central Nepal. ${ }^{8}$ Data was collected for socio-demographic characteristics and by direct observation of presence of known risk factor of dengue transmission in their household. Age more than 15 years and willing to participate was included. The informed consent was obtained prior to data collection. The confidentiality was maintained by coding the respondents' name in the questionnaire, without disclosing the respondents' information to others and using this for the study only. The collected date was checked thoroughly for completeness and coded first then it was entered in Microsoft excel. The entered data was checked, verified and was transferred to Statistical Package for Social Sciences (SPSS) 17 for analysis. 


\section{RESULTS}

A community based cross sectional study was conducted in Haraincha village development Committee of Morang District of Eastern Nepal. Data was collected from 122 households

As shown in table 1, the study finding revealed that the male respondents were more $(61.5 \%)$ than female.
Every three in 10 belonged to age group of $31-40$ years. The majority were Brahmin/Chhetri (36.9\%) followed by Terai caste (36.1\%). Every four in five were married. Every 3 in 10 had completed their secondary level of education having major occupation as agriculture (45.9\%). Almost half were from nuclear family having average family size of 5.76 . Fifty four percent were above the poverty line.

Table 1: Distribution of respondents by socio-demographic characteristics ( $n=122$ )

\begin{tabular}{|c|c|c|}
\hline Characteristics & Number $(n=122)$ & Percentage (\%) \\
\hline \multicolumn{3}{|l|}{ Gender } \\
\hline Male & 75 & 61.5 \\
\hline Female & 47 & 38.5 \\
\hline \multicolumn{3}{|l|}{ Age (years) } \\
\hline $16-20$ & 11 & 9.0 \\
\hline $1-30$ & 32 & 26.2 \\
\hline $31-40$ & 37 & 30.3 \\
\hline $41-50$ & 15 & 12.3 \\
\hline $51-60$ & 16 & 14.2 \\
\hline \multirow{2}{*}{$61+$} & 11 & 9.0 \\
\hline & Mean $\pm S D: 37.93 \pm 14.28 \quad$ Minimum 16 Maximum 7 & \\
\hline \multicolumn{3}{|l|}{ Caste / Ethnicity } \\
\hline Brahmin/Chhetri & 45 & 36.9 \\
\hline Kirat & 11 & 9.0 \\
\hline Newar & 17 & 13.9 \\
\hline Dalit & 5 & 4.1 \\
\hline Terai caste & 44 & 36.1 \\
\hline \multicolumn{3}{|l|}{ Marital status } \\
\hline \multicolumn{3}{|l|}{ Married } \\
\hline \multicolumn{3}{|l|}{ Never married } \\
\hline \multicolumn{3}{|l|}{ Educational Status } \\
\hline Iliterate & 9 & 7.4 \\
\hline Primary & 30 & 24.6 \\
\hline Lower Secondary & 18 & 14.8 \\
\hline Secondary & 37 & 30.3 \\
\hline Higher Secondary & 21 & 17.2 \\
\hline Bachelor and above & 7 & 5.7 \\
\hline \multicolumn{3}{|l|}{ Occupational Status } \\
\hline Agriculture & 56 & 45.9 \\
\hline Service & 13 & 10.7 \\
\hline Business & 13 & 10.7 \\
\hline Labour & 6 & 4.8 \\
\hline Teaching & 9 & 7.4 \\
\hline Health Care Provider & 5 & 4.1 \\
\hline Student & 10 & 8.2 \\
\hline Unemployed & 10 & 8.2 \\
\hline \multicolumn{3}{|l|}{ Family Types } \\
\hline Nuclear & 57 & 46.7 \\
\hline Joint/Extended & 37 & 30.3 \\
\hline Three Generation & 28 & 23.0 \\
\hline \multicolumn{3}{|l|}{ Per Capita Income* } \\
\hline Above poverty line & 66 & 54.0 \\
\hline Below poverty line & 56 & 46.0 \\
\hline
\end{tabular}

* poverty line $=<1.25 \$ /$ person/day 
As shown in figure 1, two percent had history of dengue contracted outside the country. No history of death due to dengue was noticed. Almost 25\% had history of travel outside the country during last 1 year. Majority travelled to Malaysia, where dengue was known epidemic.

Figure 1: History of dengue in respondent $(n=122)$

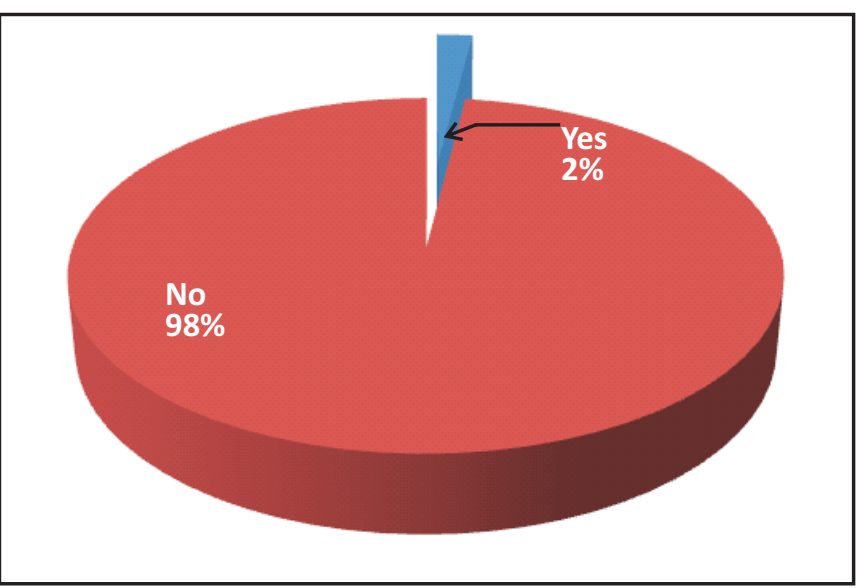

As shown in figure 2, common risk factors observed in their household were poor drainage system (79\%), bad natural light (75\%), paddy field nearby household (51\%), water filled open containers (44\%), big plant near household (31\%), and flower vases that collect stagnant water $(26 \%)$ etc.

\section{DISCUSSION}

In the present study, we found that male respondents were more $(61.5 \%)$ than female having the mean age of 38 years whereas study by Kamath R et al in Udupi Taluk, Karnataka found that majority of the respondents were females (70.6\%) with median age of the respondents 42 years. ${ }^{9}$ In the present study $7.4 \%$ were illiterate where as in a study by Kamath $\mathrm{R}$ et al where illiterate is more than double (15\%). ${ }^{9}$ In the present study, majority had agriculture as their occupation (45.9\%) having average family size of 5.76. In the present study, fifty four percent were above the poverty line.

In the present study, poor drainage (79\%), poor natural light (75\%), paddy field nearby (51\%) water filled open containers (44\%) were observed as known risk factors for dengue transmission where a study by Kamath $\mathrm{R}$ et al found that $26 \%$ of total respondents had open drainage system and water container without cover around the houses was $50.8 \%$, which is more than the present study. ${ }^{9}$ In Vietnam, people living in homes with gardens or water tanks had a threefold higher risk. ${ }^{10}$ Vehicle tires have played a major role in the international spread of dengue. ${ }^{11}$

In the Present study, big plant nearby household was found in $31 \%$ of the observed household. Kamath R et al, in Udupi Taluk reported that half of the houses had water containers

Figure 2: Assessment of risk factors for dengue in respondent household $(n=122)$

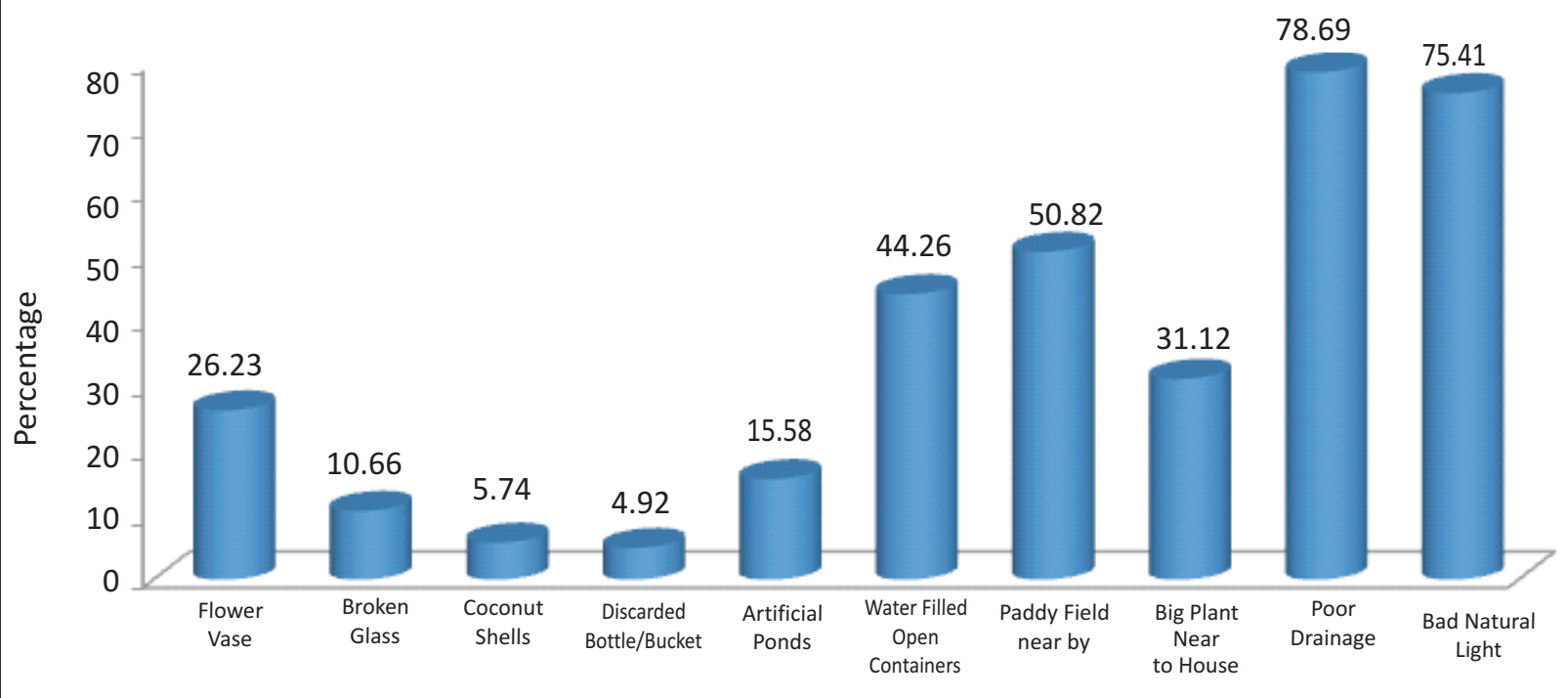


without covers around the house and $20 \%$ inside the house, which were not used in the past 1 week. Similarly trash was also found to be discarded indiscriminately around most homes (67\%). ${ }^{9}$ In Pakistan, poor condition of the house, such as uncovered latrine water tank or leaked water pipes, was a highly significant risk factor for the presence of Aedes foci. ${ }^{12}$ D. T. T. Toan et al found that environmental factors have a powerful influence on the appearance of dengue. Simple interventions could help; in our study, people living in houses with uncovered water tanks were 7.9 times more likely to get dengue fever. Those in houses discharging sewage directly into ponds had a 5.9 times higher risk than those in houses with sanitary sewage systems. ${ }^{13}$ In the present study, flower vases were noted in $26 \%$ of the observed household where as a study by Kamath $\mathrm{R}$ et al found flower pots filled with water in or around houses $(15 \%){ }^{9}$ A study by Fulmali et al in Maharashtra found that water in plastic containers was one of the risk factor of dengue transmission. ${ }^{14}$ According to Gupta $P$. unused and unprotected outdoor containers were the highest contributors to mosquito breeding. ${ }^{15}$ Similarly Kamath R et al, in Udupi Taluk, reported that foremost factor for dengue transmission was coconut shells abundance around houses (73\%), which are not properly disposed and forming constructive environment for breeding of mosquitoes. $^{9}$

\section{CONCLUSION}

The known risk factors for dengue transmission were present. As few people had contracted dengue outside the country and Haraincha Village Development Committee is near to Jhapa district favours a very conducive environment of dengue outbreak anytime. Transmission of dengue virus

\section{REFERENCES}

1. Dengue and severe Dengue, Fact sheet $\mathrm{N}^{\circ} 117$, Updated April 2016, access at www. who.int/media-centre/factsheets/fs117/en/

2. Comprehensive Guidelines for Prevention and Control of Dengue and Dengue Haemorrhagic Fever By WHO SEARO 2011

3. Bhatt S, Gething PW, Brady OJ, Messina JP, Farlow AW, Moyes CL et.al. The global distribution and burden of dengue. Nature; 496:504-507

4. Brady OJ, Gething PW, Bhatt S, Messina JP, Brownstein JS, Hoen AG et al. Refining the global spatial limits of dengue virus transmission by evidence-based consensus. PLoS Negl Trop Dis. 2012;6: e1760. doi: 10.1371/journal. pntd. 0001760

5. "National Dengue Guidelines for Clinical Management, Prevention and Control", Epidemiology and Disease Control Division, Department of Health Services, Ministry of Health \& Population, Kathmandu, Nepal 2011

6. Dengue and severe Dengue, Fact sheet $\mathrm{N}^{\circ} 117$, November 2012 , access at www. who.int/mediacentre/factsheets/fs117/en

7. Anita Acharya, K. Goswami, S. Srinath \& A. Goswami "Awareness about dengue syndrome and related preventive practices amongst residents of an urban resettlement colony of south Delhi", J Vect Borne Dis 42, September 2005, pp 122-127

8. Milan Lopchan, Bhaumika Sharma, Sudhir Regmi, Bijay Aryal, Mamata Sharma, "Knowledge and attitude of Dengue Fever among clients from Dengue prevalent areas", International Journal of Pharmaceutical and Biological Archives 2012;3(6): 1383-1388) can be prevented through control of the vectors, prevention of stagnation of water, control of breeding of mosquitoes through proper environmental management and prevention of man and Aedes mosquito's contact.

\section{RECOMMENDATIONS}

The known risk factors for potential dengue transmission were found. Awareness regarding prevention of dengue transmission must be provided to the local people through advocacy, social mobilization and legislation. The possible environmental risk factors should be managed properly through the involvement of grass root level workers in advocating behavior change at the level of individual, family and the community.

\section{LIMITATION OF THE STUDY}

The search for vector Aedes mosquitoes and its larva is better to know about the potential transmission of dengue in that area but we are unable to collect those information due to technical constraints.

\section{ACKNOWLEDGEMENT}

We would like to acknowledge all respondents for their support, time and participation, without them this study wouldn't have been possible.

\section{CONFLICT OF INTEREST}

We declare no conflict of interest.
9. Kamath R, Gupta R, Chandrasekaran V, Pattanshetty S. Assessment of environmental factors associated with dengue transmission in Udupi Taluk, Karnataka.JSciSoc2013;40:159-61

10. Be PV, et al. Evaluation on knowledge, attitude and practice of people about dengue fever in two communes of An Giang province, Vietnam in 2004. Journal of Preventive Medicine 2005; 3: 56-64

11. Hawley WA, Reiter P, Copeland RS, Pumpuni CB, Craig GB Jr, 1987. Aedes albopictus in North America: probable introduction in used tires from northern Asia. Science 236: 1114-1116

12. Heukelbach J, et al. Risk factors associated with an outbreak of Dengue fever in a favela in Fortaleza, northeast Brazil, Tropical Medicine \& International Health 2001; 6: 635-642

13. D. T. T. Toan, L. N. Hoat, W. Hu, P. Wright \& P. Martens, Risk factors associated with an outbreak of dengue fever/ dengue haemorrhagic fever in Hanoi, Vietnam Epidemiol. Infect., Page 1 of 5. (C) Cambridge University Press 2014

14. Fulmali PV, Walimbe A, Mahadev PV. Spread, establishment \& prevalence of dengue vector Aedes aegypti (L.) in Konkan region, Maharashtra, India. Indian J Med Res 2008; 127:589-601

15. Gupta P, Kumar P, Aggarwal OP. Knowledge, attitude and practices related to dengue in rural and slum areas of Delhi after the dengue epidemic of 1996. J Commun Dis 1998; 30:107-12 